\title{
PReS-FINAL-2220: Cochlear involvement in FMF
}

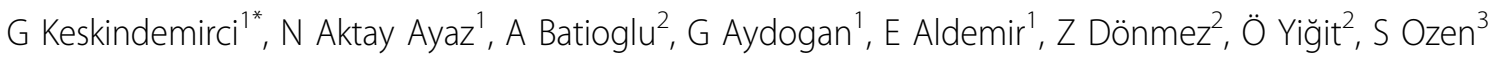 \\ From 20th Pediatric Rheumatology European Society (PReS) Congress \\ Ljubljana, Slovenia. 25-29 September 2013
}

\section{Introduction}

FMF is a monogenic autoinflammatory disease with recurring episodes of fever and serositis attacks. FMF is associated with mutations in pyrin. On the other hand mutations in a molecule in the same pathway, cryopyrin, is characterized by inflammatory features involving the inner ear as well. A study has suggested the involvement of cochlea in Behçet disease, which is a polygenic autoinflamatory disease.

\section{Objectives}

To evaluate the cochlear function of children with the diagnosis of FMF prospectively.

\section{Methods}

Children included to the study were diagnosed as FMF according to previously suggested criteria. 74 children with FMF and 20 controls were enrolled to the study. Demographic data and MEFV mutation analysis were recorded. Patients with any middle and external ear pathology were excluded from the study. After otoscopic inspection, audiometric examinations were carried out including otoacustic emission testing (OAE) by distortion products (DP) and signal noise ratio (SNR) testing with 1000, 1400, 2000, 2800 and $4000 \mathrm{~Hz}$ and audiometric evalution with pure tone average (PTA) measurements and high frequency levels of 8000, 10000, 12500, $16000 \mathrm{~Hz}$.

\section{Results}

All patients had genetic analysis for the most common mutations of our country (M694V, R202Q, E148Q, M680I, V726A, K695R). The patient group included 74 children (46 female and 28 male patient) with mean age 10.9 (range 26 months- 18 years) and the control group was age and sex matched. PTA levels were normal in both FMF patients and the control group. However, hearing levels at the frequency of $10000 \mathrm{~Hz}, 12500 \mathrm{~Hz}$ and $16000 \mathrm{~Hz}$ were found to be significantly higher in the FMF. In OAE tests, DP and SNR of FMF group was lower at $1000 \mathrm{~Hz}$ frequency.

\section{Conclusion}

The most common mutations were M694V, R202Q, E148Q, M680I, V726A, K695R. There was no correlatation between the genetic mutations and cochlear involvement. Cochlear function is very important for learning in the childhood. Like in other cryopyrinopathies, cochleovestibular involvement in FMF is probable and this may be attribueted to subclinical inflamation present during the disease course. Further studies are needed to understand whether these subtle changes are significant.

\section{Disclosure of interest}

None declared.

\section{Authors' details}

${ }^{1}$ Kanuni Sultan Suleyman Education and Research Hospital, Istanbul, Turkey.

${ }^{2}$ Istanbul Education and Research Hospital, Istanbul, Turkey.

${ }^{3}$ Hacettepe Medical Faculty, Ankara, Turkey.

Published: 5 December 2013

doi:10.1186/1546-0096-11-S2-P210

Cite this article as: Keskindemirci et al:: PReS-FINAL-2220: Cochlear involvement in FMF. Pediatric Rheumatology 2013 11(Suppl 2):P210.

${ }^{1}$ Kanuni Sultan Suleyman Education and Research Hospital, Istanbul, Turkey Full list of author information is available at the end of the article 